\title{
Oxidative Stress State Is Associated with Left Ventricular Mechanics Changes, Measured by Speckle Tracking in Essential Hypertensive Patients
}

\author{
Luis Antonio Moreno-Ruíz, ${ }^{1}$ David Ibarra-Quevedo, ${ }^{1}$ Erika Rodríguez-Martínez, ${ }^{2}$ \\ Perla D. Maldonado, ${ }^{3}$ Benito Sarabia-Ortega, ${ }^{1}$ José Gustavo Hernández-Martínez, \\ Beda Espinosa-Caleti, ${ }^{1}$ Beatriz Mendoza-Pérez, ${ }^{1}$ and Selva Rivas-Arancibia ${ }^{2}$ \\ ${ }^{1}$ UMAE Hospital de Cardiología, Centro Médico Nacional Siglo XXI, IMSS, 06720 Mexico City, DF, Mexico \\ ${ }^{2}$ Departamento de Fisiología, Facultad de Medicina, UNAM, 04510 Mexico City, DF, Mexico \\ ${ }^{3}$ Instituto Nacional de Neurología y Neurocirugía, Manuel Velasco Suárez, 14269 Mexico City, DF, Mexico
}

Correspondence should be addressed to Luis Antonio Moreno-Ruíz; luismorenomd@hotmail.com and Selva Rivas-Arancibia; srivas@unam.mx

Received 22 January 2015; Revised 24 May 2015; Accepted 29 June 2015

Academic Editor: Raj Soorappan

Copyright (c) 2015 Luis Antonio Moreno-Ruíz et al. This is an open access article distributed under the Creative Commons Attribution License, which permits unrestricted use, distribution, and reproduction in any medium, provided the original work is properly cited.

\begin{abstract}
The oxidative stress state is characterized by an increase in oxygen reactive species that overwhelms the antioxidant defense; we do not know if these pathological changes are correlated with alterations in left ventricular mechanics. The aim was correlating the oxidative stress state with the left ventricular global longitudinal strain (GLS) and the left ventricular end diastolic pressure (LVEDP). Twenty-five patients with essential hypertension and 25 controls paired by age and gender were studied. All of the participants were subjected to echocardiography and biochemical determination of oxidative stress markers. The hypertensive patients, compared with control subjects, had significantly $(p<0.05)$ higher levels of oxidized proteins $(5.03 \pm 1.05$ versus $4.06 \pm 0.63 \mathrm{nmol} / \mathrm{mg}$ ), lower levels of extracellular superoxide dismutase (EC-SOD) activity ( $0.045 \pm 0.02$ versus $0.082 \pm 0.02 \mathrm{U} / \mathrm{mg})$, higher LVEDP $(16.2 \pm 4.5$ versus $11.3 \pm 1.6 \mathrm{~mm} \mathrm{Hg})$, and lower GLS $(-12 \%$ versus $-16 \%)$. Both groups had preserved ejection fraction and the results showed a positive correlation of oxidized proteins with GLS $(r=0.386, p=0.006)$ and LVEDP $(r=0.389$, $p=0.005)$; we also found a negative correlation of EC-SOD activity with GLS $(r=-0.404, p=0.004)$ and LVEDP $(r=-0.347$, $p=0.014)$.
\end{abstract}

\section{Introduction}

An increasing body of evidence suggests that oxidative stress is involved in endothelial dysfunction, a factor that is present in the pathogenesis of many cardiovascular diseases, including hypercholesterolemia, atherosclerosis, hypertension, diabetes, and heart failure [1-4]; endothelial dysfunction is what all of these diseases have in common [5].

In healthy individuals, the endothelium plays a key role in vascular homeostasis through the release of a variety of antiatherogenic substances that exert an effect by way of platelet aggregation and adhesion inhibition, smooth muscle cell proliferation, and leukocyte adhesion [6-17].
The evidence that oxidative stress state occurs in hypertensive patients is based on increased levels of biomarkers such as oxidized protein and lipid oxidation and on the decreased activity of antioxidants such as superoxide dismutase, glutathione peroxidase, and catalase [18-20] as well as on the shorter telomere length found in these patients $[21,22]$. Some studies have revealed an association between oxidative stress, inflammation, and arterial hypertension. These factors participate in a vicious cycle that can lead to and perpetuate progressive cardiovascular diseases [23]. It is now clear that oxidative stress has an important role in the impairment of cellular signal pathways and the modulation of 
growth, apoptosis, hypertrophy, inflammation, and remodeling of cardiac muscle [24] through the activation of various signaling cascades and redox state-sensitive transcription factors $[25,26]$. ROS generates various stimuli, including angiotensin II, endothelin-1, cytokine, and growth factorinduced redox-sensitive signals, and also oxidative stress state produces the decrease of extracellular superoxide dismutase (EC-SOD) activity and increased oxidized proteins leading to the accumulation of extracellular matrix proteins, interstitial and perivascular fibrosis, and myocyte hypertrophy, which cause left ventricular (LV) remodeling as in the case of diabetic cardiomyopathy [27-29].

The evidence suggests that systolic and diastolic abnormalities in these patients begin to develop in the early stages of the disease, even when the left ventricular ejection fraction (LVEF) is still normal [30].

The ultrasound evaluation of myocardial deformation by 2-dimensional strain based on the speckle tracking of grayscale images enables the accurate quantitation of regional and global systolic function by determination of the longitudinal, circumferential, and radial deformation of myocardial fiber in the LV, providing information about structural and functional abnormalities [31, 32].

Conventional transmitral Doppler flow and assessment of mitral annular velocities by tissue Doppler allowed us to study the diastolic function by measurements of $\mathrm{E}$ velocity, $\mathrm{E} / \mathrm{E}^{\prime}$ ratio and left ventricular end diastolic pressure (LVEDP) [33-35].

The aim of this study was to correlate the oxidative stress state (levels of oxidized proteins and EC-SOD activity) with LV mechanics assessed by left ventricular global longitudinal systolic strain (GLS) and left ventricular end diastolic pressure (LVEDP).

\section{Materials and Methods}

2.1. Subjects. Subjects were adults of both genders with a previous diagnosis of essential hypertension, systolic pressure $\leq 150 \mathrm{~mm} \mathrm{Hg}$, and diastolic pressure $\leq 90 \mathrm{~mm} \mathrm{Hg}$. All hypertensive patients were on medication for blood pressure control. These patients were referred from a second level hospital to the echocardiography laboratory of the Hospital de Cardiología, CMNSXXI, IMSS. The eligibility criteria for this study included the following: ejection fraction $\geq 0.50$, sinus rhythm, NYHA functional classes I-II, and absence of other systemic disease. Fifty patients were included in this study, who were divided into two groups: twenty-five patients in essential hypertensive group (mean age $43.3 \pm 8.04$ years), of which $40 \%$ were women and also 25 patients in the control group (mean age $43.8 \pm 10.2$ years) of which $40 \%$ were also women. Patients with bidimensional echocardiographic images of poor quality or not susceptible to data analysis in QLAB software were excluded (Phillips). For control, we selected healthy subjects, paired with the hypertensive patients by gender and age. The protocol was carried out in strict accordance with ethical norms, the Declaration of Helsinki, and the regulations of the General Health Law on health research and approved by the local research committee and ethics board. All participants signed a written informed consent. All subjects refrained from eating or drinking anything for 8 to 12 hours before each of the testing sessions. Demographic data and anthropometric measurements were collected. Finally, echocardiographic images and blood samples were taken from the antecubital vein in a $7 \mathrm{~mL}$ tube $(\mathrm{BD}$ Vacutainer EDTA) at room temperature (14-24 $\left.{ }^{\circ} \mathrm{C}\right)$, which was then processed by centrifugation.

2.2. Echocardiographic Study. Two-dimensional echocardiography was performed and images were taken from patients in left lateral decubitus position using a commercially available system (Phillips iE33). Image acquisition was performed using an S5-1 transducer. The images were taken at a depth of $16 \mathrm{~cm}$ using standard parasternal and apical views (standard long-axis and 2-, 3-, and 4-chamber images) with a frame rate of 80-100 frames/s. Standard M-mode and 2D images were acquired in cine loop format, including pulsed, continuous, color, and tissue Doppler data from three consecutive heart beats. All analyses were performed offline using commercial software (QLAB, Phillips). Myocardial deformation measurements were performed using speckle tracking. A global longitudinal strain curve was obtained (Figures 1(d) and 1(e)) from each of the apical views (Figures 1(a), 1(b), and 1(c)); all LV myocardial segments were considered to be the region of interest. The average value of each peak systolic longitudinal strain from the three apical views was calculated as GLS and expressed as percentage. Estimated LVEDP values were calculated using Nagueh formula, $1.9+\left(1.24 \times \mathrm{E} / \mathrm{E}^{\prime}\right)$, and expressed as $\mathrm{mm} \mathrm{Hg} \mathrm{[36].}$

2.3. Biochemical Analyses. Blood samples were collected from the antecubital vein in two $7 \mathrm{~mL}$ tubes (Vacutainer EDTA) for biochemical analysis. Plasma samples were obtained by centrifugation at $100 \mathrm{~g}$ for 10 minutes. Plasma was separated into aliquots and frozen at $-30^{\circ} \mathrm{C}$ until assays were performed. The content of protein carbonyl in the samples was determined by the method of Reznick and Packer modified for plasma proteins [37]. Carbonyl formation was assessed on the basis of the formation of protein hydrazone by reacting with 2,4-dinitrophenylhydrazine (DNPH). Plasma aliquots were incubated overnight in streptomycin sulfate $10 \%$ to remove nucleic acids and centrifuged at $21000 \mathrm{~g}$ at $48^{\circ} \mathrm{C}$ for $40 \mathrm{~min}$. The samples were then treated with $10 \mathrm{mM}$ $\mathrm{DNPH}$ (in $\mathrm{HCl} 2.5 \mathrm{M}$ ) for $1 \mathrm{~h}$ at room temperature; afterwards, trichloroacetic acid $10 \%$ was added and the samples were centrifuged at $2500 \mathrm{~g}$ at $48^{\circ} \mathrm{C}$ for $10 \mathrm{~min}$. The pellets were washed three times with ethanol/ethyl acetate $(1: 1)$, dissolved in $6 \mathrm{M}$ guanidine hydrochloride (phosphate buffer $20 \mathrm{mM}, \mathrm{pH} 7.4$ ), incubated for $10 \mathrm{~min}$ at $37^{\circ} \mathrm{C}$, and centrifuged at $5000 \mathrm{~g}$ and $48^{\circ} \mathrm{C}$ for $3 \mathrm{~min}$ to remove insoluble material. Absorbance was measured at $370 \mathrm{~nm}$. Protein carbonyl content was expressed as nmol carbonyl/mg protein using the molar absorption coefficient of DNPH $\left(22000 \mathrm{M}^{-1} \mathrm{~cm}^{-1}\right)$. Total protein concentration was obtained by reading the optical density at $280 \mathrm{~nm}$ in blank tubes prepared in parallel (treated only with $\mathrm{HCl}$ ). The standard curve of bovine serum 


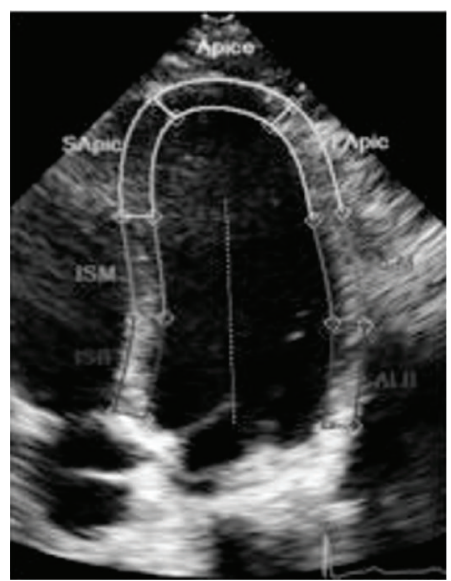

(a)

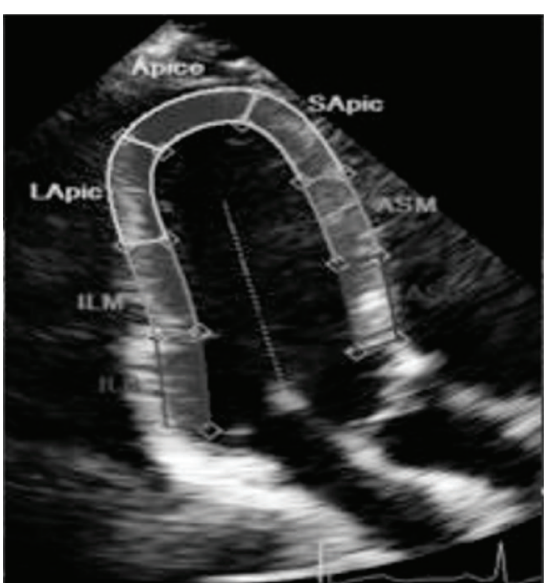

(b)

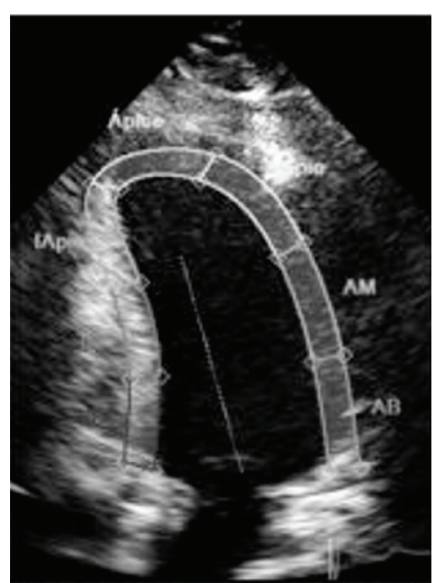

(c)

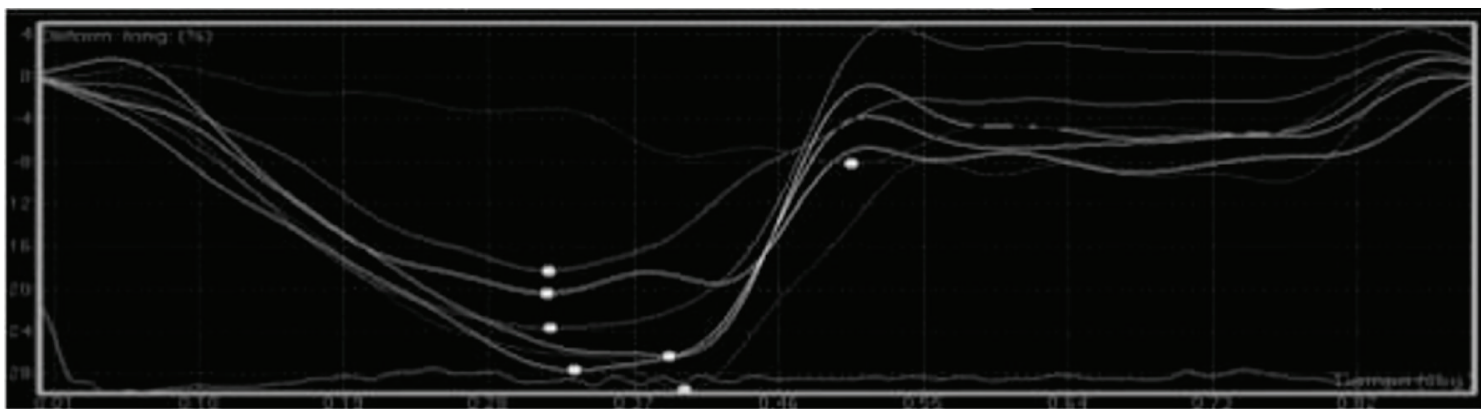

(d)

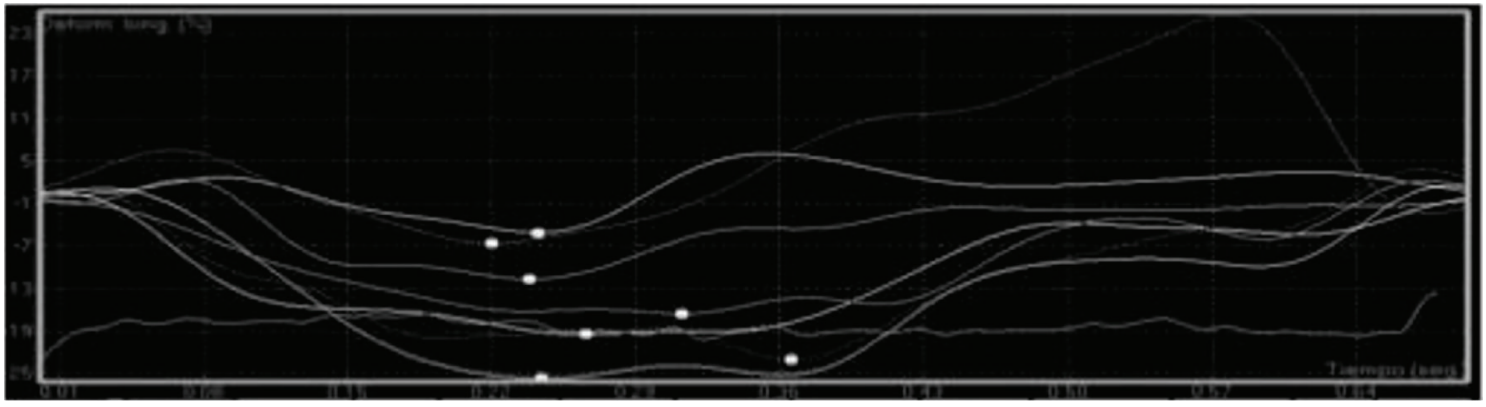

(e)

FIGURE 1: Echocardiographic determination of myocardial longitudinal deformation. Selection of regions of interest for longitudinal strain quantification in four chambers (a), three chambers (b), and two chamber (c) projections. Longitudinal strain curves of a control (d) and hypertensive (e) patient.

albumin $(0.25-2 \mathrm{mg} / \mathrm{mL})$ prepared in $6 \mathrm{M}$ guanidine- $\mathrm{HCl}$ was used for this analysis.

Extracellular superoxide dismutase (EC-SOD) activity in plasma samples was determined by the method of Oberley and Spitz [38]. In brief, competitive inhibition assays were performed using the xanthine oxidase system to reduce Nitro-Blue Tetrazolium (NBT). The mixture contained a final concentration of EDTA $0.122 \mathrm{mM}$, NBT $30.6 \mu \mathrm{M}$, xanthine $0.122 \mathrm{mM}$, bovine serum albumin $0.006 \%$, and sodium carbonate $49 \mathrm{mM}$. Five hundred $\mu \mathrm{L}$ of homogenates (diluted $1: 20$ ) was added to $2.45 \mathrm{~mL}$ of the mixture described above. Afterwards, $50 \mu \mathrm{L}$ of xanthine oxidase was added in a final concentration of $2.8 \mathrm{U} / \mathrm{L}$ and the mixture was incubated in a water bath at $27^{\circ} \mathrm{C}$ for $30 \mathrm{~min}$. The reaction was stopped with $1 \mathrm{~mL}$ of $0.8 \mathrm{mM}$ cupric chloride and the optical density was read at $560 \mathrm{~nm}$. One hundred percent of NBT reduction was obtained in a different tube in which the sample was replaced by distilled water. The amount of protein involved in inhibiting the reduction of NBT to $50 \%$ of the maximum was defined as one unit of SOD activity. The results were expressed as $\mathrm{U} / \mathrm{mg}$ protein.

2.4. Statistical Analysis. The data were analyzed with IBM SPSS statistical software 21.0. Quantitative variables were expressed as means \pm SD or median (interquartile range) according to their distribution. Comparisons between groups 
TABLE 1: Anthropometric and demographic variables of both study groups.

\begin{tabular}{lcc}
\hline Variables & $\begin{array}{c}\text { Group I: control } \\
(n=25)\end{array}$ & $\begin{array}{c}\text { Group II: } \\
\text { hypertension } \\
(n=25)\end{array}$ \\
\hline Age (years) & $43.3 \pm 8.04$ & $43.8 \pm 10.2$ \\
Women & $10(40)$ & $10(40)$ \\
Weight $(\mathrm{kg})$ & $68.9 \pm 10.8^{*}$ & $79.8 \pm 12.4^{*}$ \\
Height $(\mathrm{m})$ & $1.65 \pm 0.1$ & $1.64 \pm 0.1$ \\
Corporal mass index $\left(\mathrm{kg} / \mathrm{m}^{2}\right)$ & $24.8 \pm 1.0^{*}$ & $29.4 \pm 1.8^{*}$ \\
Systolic pressure $(\mathrm{mm} \mathrm{Hg})$ & $100(80-120)^{\dagger}$ & $130(90-150)^{\dagger}$ \\
Diastolic pressure $(\mathrm{mm} \mathrm{Hg})$ & $60(50-80)^{\dagger}$ & $70(60-90)^{\dagger}$ \\
Heart rate $(\mathrm{bpm})$ & $67(56-75)$ & $70(60-90)$ \\
\hline
\end{tabular}

Values represent means $\pm \mathrm{SD}$, median (minimum-maximum) or $n$ (percent). ${ }^{*} p<0.05$ (Student's $t$-test), ${ }^{\dagger} p<0.05$ (Mann-Whitney $U$ test).

were performed using Student's $t$-test or Mann Whitney $U$ test. Pearson's linear correlation was used to determine whether there is an association between biomarkers of oxidative stress and global LV longitudinal strain or LV telediastolic pressure. Multivariate analysis was used. A value of $p<0.05$ was considered significant.

\section{Results}

Twenty-five healthy subjects (age $43.3 \pm 8$ years) and 25 patients with hypertension (aged $43.8 \pm 10.2$ years) were two groups, both groups with similar ages. Anthropometric and clinical variables are presented in Table 1 . We detected a higher prevalence of overweight in the essential hypertension group evaluated by body mass index $(24.8 \pm 1.0$ versus $29.4 \pm$ $1.8, p<0.05)$.

\subsection{Echocardiographic Outcomes}

3.1.1. Two-Dimensional Data Analysis and Systolic Function. The analysis by conventional methods showed that the hypertension group had larger left atrial diameter (39 versus $35 \mathrm{~mm} ; p<0.05$ ) and volume (49.3 versus $33.9 \mathrm{~mL} ; p<0.05$ ), LV concentric hypertrophy (13 versus $10 \mathrm{~mm} ; p<0.05$ ), and lower LV systolic end volume (22 versus $25 \mathrm{~mL} ; p<0.05$ ). Both groups had preserved LV ejection fraction, by Simpson's modified method. Taken together the body of data reveals homogeneity in systolic function (Table 2).

3.1.2. Diastolic Function. In the hypertensive group, by pulsed Doppler we observed lower values of $\mathrm{E}$ wave velocity (61 versus $77 \mathrm{~cm} / \mathrm{s} ; p<0.05$ ), higher values of A wave velocity (92 versus $56 \mathrm{~cm} / \mathrm{s} ; p<0.05$ ), higher values of deceleration of mitral flow time (257 versus $194 \mathrm{~ms}$ ), and higher values of isovolumetric relaxation time (123 versus $77 \mathrm{~ms}$ ), that is, mild diastolic dysfunction. By tissular Doppler, in the hypertensive group we observed higher values of the $\mathrm{E} / \mathrm{E}^{\prime}$ ratio $(10.2 \pm 3.1$ versus $6.6 \pm 1.1, p<0.05)$ and higher levels of LVEDP estimated by Nagueh formula (16.2 \pm 4.5 versus $11.3 \pm 1.6 \mathrm{~mm} \mathrm{Hg}$ ), both consistent with diastolic dysfunction.
TABLE 2: Conventional echocardiographic measurements in both study groups.

\begin{tabular}{lcc}
\hline Variables & $\begin{array}{c}\text { Group I: control } \\
(n=25)\end{array}$ & $\begin{array}{c}\text { Group II: } \\
\text { hypertension } \\
(n=25)\end{array}$ \\
\hline LA $(\mathrm{mm})$ & $35(26-40)^{\dagger}$ & $39(33-48)^{\dagger}$ \\
RA $(\mathrm{mm})$ & $37(32-41)$ & $38(35-49)$ \\
LVDD $(\mathrm{mm})$ & $44.3 \pm 4.2$ & $43.9 \pm 2.9$ \\
LVSD $(\mathrm{mm})$ & $26 \pm 3.6$ & $25.6 \pm 2.9$ \\
S $(\mathrm{mm})$ & $10(8-11)^{\dagger}$ & $13(9-14)^{\dagger}$ \\
PW $(\mathrm{mm})$ & $10(8-11)^{\dagger}$ & $13(9-14)^{\dagger}$ \\
RVDD (mm) & $26(23-30)^{\dagger}$ & $28(25-32)^{\dagger}$ \\
AoR $(\mathrm{mm})$ & $30(25-35)$ & $31(27-35)$ \\
AoA $(\mathrm{mm})$ & $20(17-22)$ & $20(17-21)$ \\
LVESV $(\mathrm{mL})$ & $25(13-42)^{*}$ & $22(16-39)^{*}$ \\
LAV $(\mathrm{mL})$ & $32.12 \pm 12.2^{*}$ & $49.3 \pm 10.4^{*}$ \\
RAV $(\mathrm{mL})$ & $33.9 \pm 11.4^{*}$ & $43.6 \pm 13.1^{*}$ \\
PSP $(\mathrm{mm} \mathrm{Hg})$ & $25.5 \pm 3.3^{*}$ & $29.2 \pm 5.5^{*}$ \\
LVEF & $0.70 \pm 0.05$ & $0.70 \pm 0.06$ \\
\hline
\end{tabular}

Values represent means \pm SD, median (minimum-maximum). LA: left atrium; RA: right atrium; LVDD: left ventricle diastolic diameter; LVSD: left ventricle systolic diameter; S: interventricular septum; PW: posterior wall; RVDD: right ventricle diastolic diameter; AoR: aortic root; AoA: aortic annulus; LVESV: left ventricle end systolic volume; LAV: left atrial volume; RAV: right atrial volume; PSP: pulmonary systolic pressure; LVEF: left ventricle ejection fraction. ${ }^{*} p<0.05$ (Student's $t$-test), ${ }^{\dagger} p<0.05$ (MannWhitney $U$ test).

3.1.3. Left Ventricle Global Longitudinal Deformation. With respect to the evaluation of ventricular mechanics by speckle tracking, the hypertension group showed lower longitudinal deformation than controls, $-12.6(-6.4$ to -15.8$)$ versus -16.9 $(-13.1$ to -22$)$, respectively, (Table 3, Figures $1(\mathrm{~d})$ and $1(\mathrm{e})$ ), which confirms the diastolic dysfunction even when the LVEF is normal, that is, early left ventricular mechanical changes, detected by this echocardiographic technique.

3.2. Biochemical Outcomes. Biochemical evaluation revealed a total activity of EC-SOD lower in hypertensive patients when they were compared with the control group (0.045 \pm 0.02 versus $0.082 \pm 0.02 \mathrm{U} / \mathrm{mg}, p<0.005)$; this can be explained by the chronic state of oxidative stress in these patients (Figure 2(a)). This is shown by the increased levels of oxidized protein, which were 24 percent higher in hypertensive patients versus controls $(5.0350 \pm 1.05$ versus $4.0631 \pm 0.63, p<0.05)$ (Figure 2(b)).

3.3. Correlation between Oxidative Stress and Left Ventricular Mechanics by Speckle Tracking. Figures 3(a) and 3(c) show a negative correlation of total superoxide dismutase activity with GLS $(r=-0.404, p=0.004)$ and $\operatorname{LVEDP}(r=-0.347$, $p=0.014)$. Figures $3(\mathrm{~b})$ and $3(\mathrm{~d})$ show a positive correlation of the levels of oxidized proteins with GLS ( $r=0.386, p=$ $0.006)$ and $\operatorname{LVEDP}(r=0.389, p=0.005)$. 


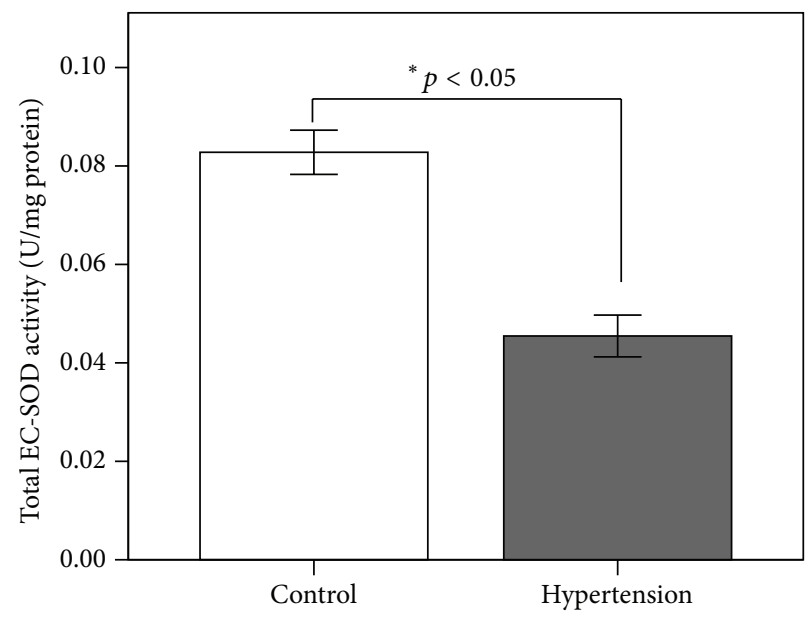

(a)

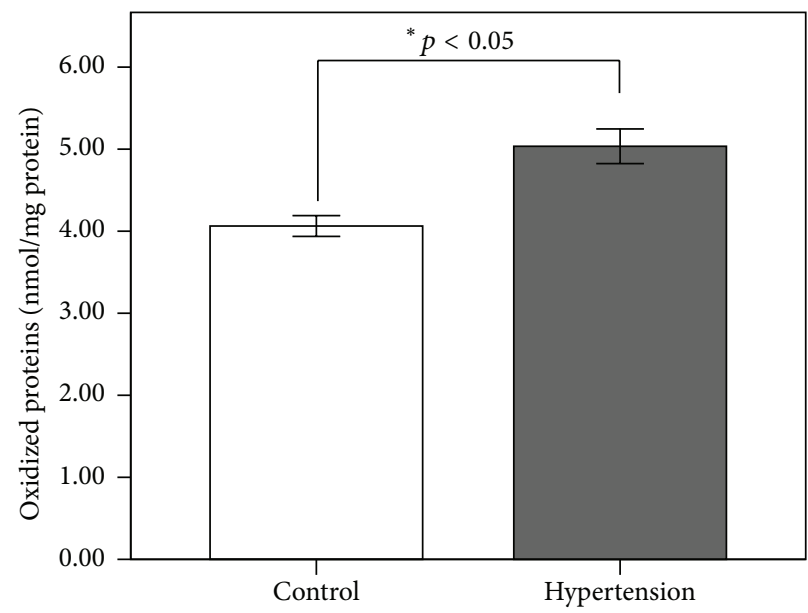

(b)

FIGURE 2: Total activity of EC-SOD (a) and levels of oxidized proteins (b) in control and hypertensive group. EC-SOD: extracellular superoxide dismutase. Student's $t$-test.

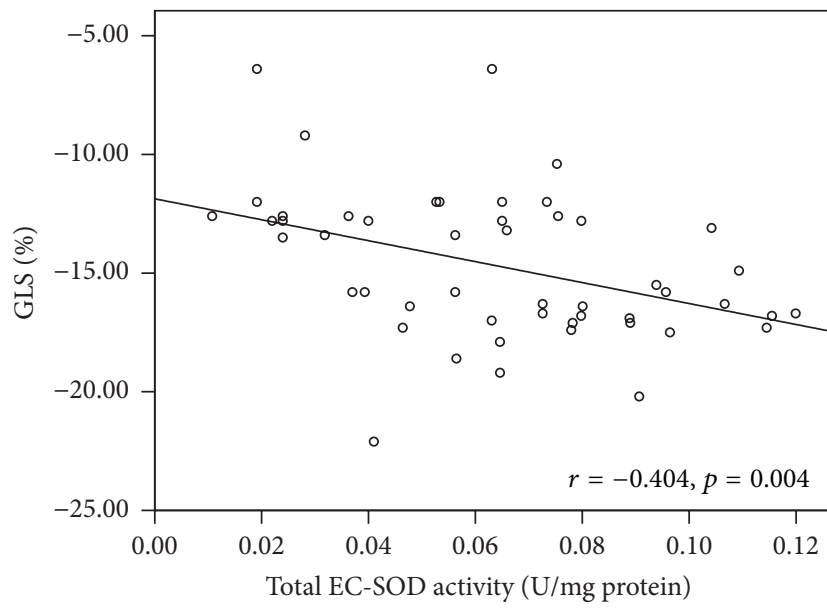

(a)

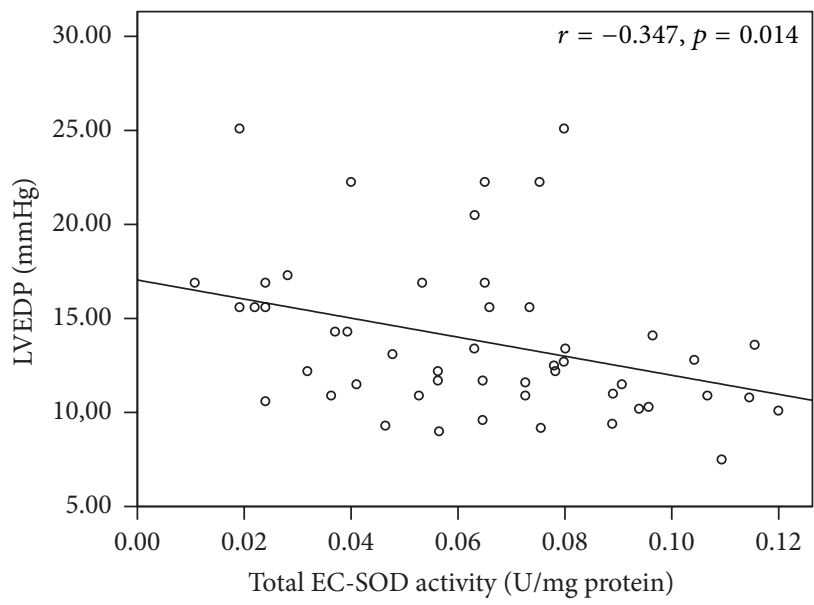

(c)

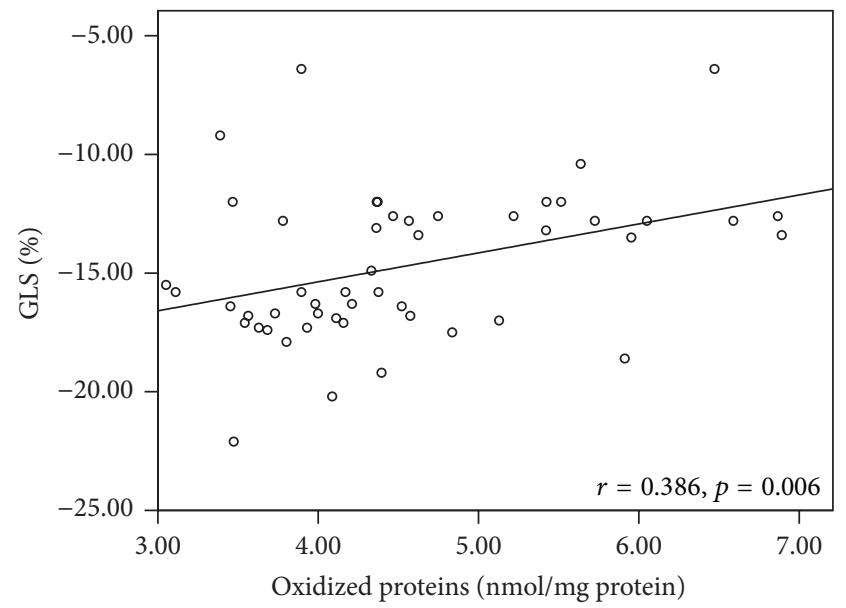

(b)

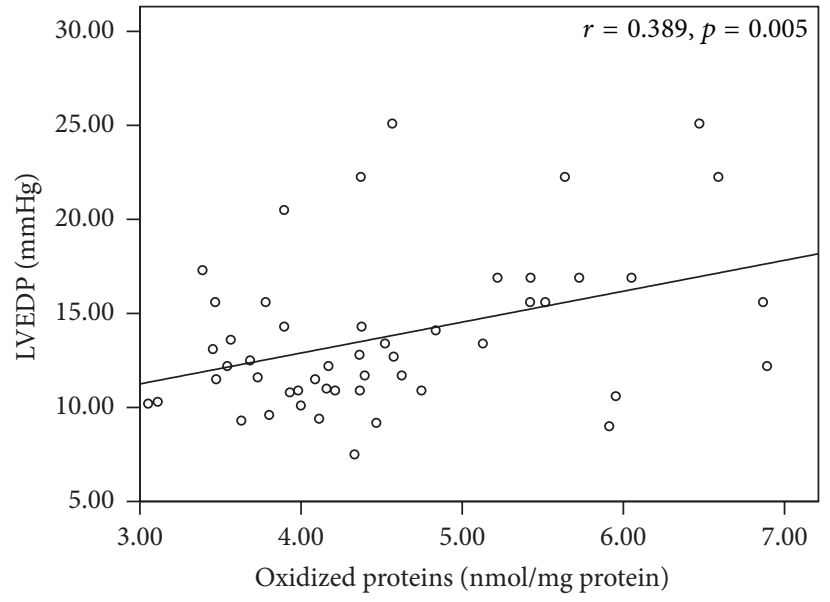

(d)

FIGURE 3: Relationship between global longitudinal strain and extracellular superoxide dismutase activity (a) and oxidized proteins (b). Relationship between left ventricular end diastolic pressure and total extracellular superoxide dismutase activity (c) and oxidized proteins (d). GLS: global longitudinal strain; EC-SOD: extracellular superoxide dismutase; LVEDP: left ventricular end diastolic pressure. 
TABLE 3: Ventricular mechanics parameters measured by pulsed, Mcolor, and tissular Doppler and speckle tracking.

\begin{tabular}{lcc}
\hline Variables & $\begin{array}{c}\text { Group I: control } \\
(n=25)\end{array}$ & $\begin{array}{c}\text { Group II: } \\
\text { hypertension } \\
(n=25)\end{array}$ \\
\hline E wave, cm/s & $77(49-118)^{\dagger}$ & $61(44-87)^{\dagger}$ \\
A wave, cm/s & $56(38-94)^{\dagger}$ & $92(67-103)^{\dagger}$ \\
E/A ratio & $1.2(1.0-2.2)^{\dagger}$ & $0.7(0.6-0.9)^{\dagger}$ \\
DT, ms & $194(127-246)^{\dagger}$ & $257(194-300)^{\dagger}$ \\
IRT, ms & $77(63-95)^{\dagger}$ & $123(103-140)^{\dagger}$ \\
$\mathrm{E}^{\prime}$ wave, cm/s & $11.7 \pm 1.9^{*}$ & $6.3 \pm 2.04^{*}$ \\
$\mathrm{~A}^{\prime}$ wave, cm/s & $8.3 \pm 1.7^{*}$ & $8.8 \pm 1.0^{*}$ \\
E/E' ratio & $6.6 \pm 1.1^{*}$ & $10.2 \pm 3.1^{*}$ \\
LVEDP, mm Hg & $11.3 \pm 1.6^{*}$ & $16.2 \pm 4.5^{*}$ \\
PV color, cm/s ${ }^{2}$ & $69(52-99)^{\dagger}$ & $40(23-48)^{\dagger}$ \\
GLS, \% & $-16.9(-13.1$ to & $-12.6(-6.4$ to \\
& $-22)^{\dagger}$ & $-15.8)^{\dagger}$ \\
\hline
\end{tabular}

Values represent means $\pm \mathrm{SD}$, median (minimum-maximum). DT: E wave deceleration time; IRT: isovolumetric relaxation time; LVEDP: left ventricle end diastolic pressure (by Nagueh formula); PV color: transmitral color propagation velocity; GLS: left ventricle global longitudinal strain. ${ }^{*} p<0.05$ (Student's $t$-test), ${ }^{\dagger} p<0.05$ (Mann-Whitney $U$ test).

Multivariate analysis revealed no significant differences adjusted for confusors variables (age, weight, body mass index, and antihypertensive treatment).

\section{Discussion}

The oxidative stress state is characterized by an increase in the amount of reactive oxygen and nitrogen species that overwhelms the antioxidant defense systems of the body; this state is present in some chronic cardiovascular diseases such as hypertension.

All subjects in our study group were hypertensive and overweight, a common situation in emergent forms of the metabolic syndrome. However, due to the selection criteria, our group of patients did not fulfill the diagnosis of metabolic syndrome, and the multivariate analysis controlling for confusion variables did not show a statistically significant association.

The echocardiographic determination of atrial and LV dimensions in hypertensive patients clearly indicated that this group of patients had concentric LV hypertrophy, as the patients reported by $\mathrm{Qu}$ and collaborators [39], and that it was associated with the highest degree of diastolic dysfunction.

Wang et al. [32] demonstrated that, in patients with preserved systolic function and cardiac insufficiency data suggesting diastolic dysfunction, the values of GLS decreased compared with healthy controls, reporting an average of $-12 \pm 2 \%$, whereas in our study we found a median GLS of $-12.6 \%$ ( -6.4 to -15.8$)$. We found a positive correlation between oxidized proteins and GLS; that is, the greater the oxidative stress state (higher levels of oxidized proteins), the lower the myocardial longitudinal deformation (positive values of GLS) and the worse the systolic function, even with preserved LVEF. In addition, we confirmed a negative correlation between EC-SOD activity and GLS; that is, the lower the antioxidant defense state, the lower the myocardial deformation or the worse systolic function.

Sohn et al. [40] and Kasner et al. [35] reported that in diastolic dysfunction the $\mathrm{E}^{\prime}$ wave velocity is lower and the tissue Doppler $A^{\prime}$ wave is longer, a situation that we observed in the hypertensive group.

The hypertensive group showed values of $\mathrm{E} / \mathrm{E}^{\prime}>10$, a parameter that has been associated with high left ventricular end diastolic pressure and that, according to Sohn et al. [40], has shown a sensitivity of $75 \%$ and a specificity of $93 \%$ (the mean in our study was $16.2 \pm 4.5 \mathrm{~mm} \mathrm{Hg}$ ).

On the basis of these findings, we argue that hypertensive patients have diastolic dysfunction, as documented by Doppler transmitral flow propagation velocity, color, mitral annular velocity, and higher LVEDP than controls.

Vaziri and Rodríguez-Iturbe [23] showed an increase in the production of reactive oxygen species in patients with essential, renovascular, and malignant hypertension, as well as preeclampsia; these findings were generally based on an increase in the plasma levels of reactive biomarkers of lipid peroxidation and oxidative stress. We found similar results in our study, reporting lower levels of EC-SOD activity in the hypertensive group.

Shizukuda et al. [41] reported a positive correlation $(r=$ 0.32, $p=0.001$ ) between peroxidized lipid concentrations and the degree of diastolic dysfunction as measured by the speed of the A wave. We found the same positive correlation between the levels of oxidized proteins and LVEDP; in other words, the greater the states of oxidative stress, the higher the LVEDP and also the worse the diastolic dysfunction, even with preserved LVEF.

Furthermore, Sagar et al. [42] reported that the decrease of antioxidant activity (superoxide dismutase) and decreased levels of scavengers of reactive oxygen species may contribute to oxidative stress state. Our results were consistent with a negative correlation between EC-SOD activity and LVEDP; that is, the higher values of LVEDP, the lower values of the antioxidant activity of EC-SOD.

\section{Conclusion}

An increase in the levels of oxidized proteins and reduced antioxidant defenses (oxidative stress state) in essential hypertensive patients are correlated with a worse systolic function as measured by left ventricular global longitudinal systolic strain, which decreases even with normal left ventricular ejection fraction; they are also correlated with a reduced diastolic function as measured by an increase in left ventricular end diastolic pressure, both measured by echocardiography.

\section{Conflict of Interests}

The authors declare that they have no conflict of interests. 


\section{Authors' Contribution}

Luis Antonio Moreno-Ruíz and Selva Rivas-Arancibia participated in the design research, wrote the paper, and analyzed data. David Ibarra-Quevedo, Perla D. Maldonado, Benito Sarabia-Ortega, José Gustavo Hernández-Martínez, Beda Espinosa-Caleti, and Beatriz Mendoza-Pérez carried out research experiments. Erika Rodríguez-Martínez participated in the realization of this study and carried out research experiments.

\section{Acknowledgment}

This work was supported by the Dirección General de Apoyo al Personal Académico (Grant no. IN221114 to Selva RivasArancibia).

\section{References}

[1] K. B. Beckman and B. N. Ames, "The free radical theory of aging matures," Physiological Reviews, vol. 78, no. 2, pp. 547-581, 1998.

[2] W. Dröge, "Free radicals in the physiological control of cell function," Physiological Review, vol. 82, no. 1, pp. 47-95, 2002.

[3] G. J. Burton and E. Jauniaux, "Oxidative stress," Best Practice \& Research Clinical Obstetrics \& Gynaecology, vol. 25, no. 3, pp. 287-299, 2011.

[4] H. Cai and D. G. Harrison, "Endothelial dysfunction in cardiovascular diseases: the role of oxidant stress," Circulation Research, vol. 87, no. 10, pp. 840-844, 2000.

[5] A. Ceriello, "Possible role of oxidative stress in the pathogenesis of hypertension," Diabetes care, vol. 31, supplement 2, pp. S181S184, 2008.

[6] T. J. Anderson, "Assessment and treatment of endothelial dysfunction in humans," Journal of the American College of Cardiology, vol. 34, no. 3, pp. 631-638, 1999.

[7] D. D. Thomas, L. A. Ridnour, J. S. Isenberg et al., "The chemical biology of nitric oxide: implications in cellular signaling," Free Radical Biology and Medicine, vol. 45, no. 1, pp. 18-31, 2008.

[8] W. K. Alderton, C. E. Cooper, and R. G. Knowles, "Nitric oxide synthases: structure, function and inhibition," Biochemical Journal, vol. 357, no. 3, pp. 593-615, 2001.

[9] J. Tamargo, R. Caballero, R. Gómez, L. Núñez, M. Vaquero, and E. Delpón, "Efectos del óxido nítrico sobre la función cardíaca," Revista Española de Cardiologia, vol. 6, supplement A, pp. 3A20A, 2006.

[10] P. Verdejo, "Función endotelial," Archivos de Cardiología de México, vol. 76, pp. 164-169, 2006.

[11] G. Zalba, G. S. José, M. U. Moreno et al., "Oxidative stress in arterial hypertension: role of $\mathrm{NAD}(\mathrm{P}) \mathrm{H}$ oxidase," Hypertension, vol. 38, no. 6, pp. 1395-1399, 2001.

[12] K. Nakazono, N. Watanabe, K. Matsuno, J. Sasaki, T. Sato, and M. Inoue, "Does superoxide underlie the pathogenesis of hypertension?" Proceedings of the National Academy of Sciences of the United States of America, vol. 88, no. 22, pp. 10045-10048, 1991.

[13] V. Pialoux, A. D. Brown, R. Leigh, C. M. Friedenreich, and M. J. Poulin, "Effect of cardiorespiratory fitness on vascular regulation and oxidative stress in postmenopausal women," Hypertension, vol. 54, no. 5, pp. 1014-1020, 2009.
[14] M. McIntyre, D. F. Bohr, and A. F. Dominiczak, "Endothelial function in hypertension: the role of superoxide anion," Hypertension, vol. 34, no. 4, pp. 539-545, 1999.

[15] B. R. Silva, L. Pemomian, and L. M. Bendhack, "Contribution of oxidative stress to endothelial dysfunction in hypertension," Frontiers in Physiology, vol. 3, article 441, 2012.

[16] L. Badimón and J. Martínez-González, "Disfunción endotelial," Revista Española de Cardiología Suplementos, vol. 6, no. 1, pp. 21A-30A, 2006.

[17] R. Rodrigo, W. Passalacqua, J. Araya, M. Orellana, and G. Rivera, "Implications of oxidative stress and homocysteine in the pathophysiology of essential hypertension," Journal of Cardiovascular Pharmacology, vol. 42, no. 4, pp. 453-461, 2003.

[18] R. M. Touyz, "Reactive oxygen species, vascular oxidative stress, and redox signaling in hypertension: what is the clinical significance?" Hypertension, vol. 44, no. 3, pp. 248-252, 2004.

[19] J. Redón, M. R. Oliva, C. Tormos et al., "Antioxidant activities and oxidative stress byproducts in human hypertension," Hypertension, vol. 41, no. 5, pp. 1096-1101, 2003.

[20] J. Pedro-Botet, M. I. Covas, S. Martín, and J. Rubiés-Prat, "Decreased endogenous antioxidant enzymatic status in essential hypertension," Journal of Human Hypertension, vol. 14, no. 6, pp. 343-345, 2000.

[21] C. Armani, N. Botto, M. G. Andreassi, and E. Centaro, "Molecular markers of cardiovascular damage in hypertension," Current Pharmaceutical Design, vol. 19, no. 13, pp. 2341-2350, 2013.

[22] S. Demissie, D. Levy, E. J. Benjamin et al., "Insulin resistance, oxidative stress, hypertension, and leukocyte telomere length in men from the Framingham Heart Study," Aging Cell, vol. 5, no. 4, pp. 325-330, 2006.

[23] N. D. Vaziri and B. Rodríguez-Iturbe, "Mechanisms of disease: oxidative stress and inflammation in the pathogenesis of hypertension," Nature Clinical Practice Nephrology, vol. 2, no. 10, pp. 582-593, 2006.

[24] D. D. Heistad, Y. Wakisaka, J. Miller, Y. Chu, and R. Pena-Silva, "Novel aspects of oxidative stress in cardiovascular diseases," Circulation Journal, vol. 73, no. 2, pp. 201-207, 2009.

[25] Y. Higashi, K. Noma, M. Yoshizumi, and Y. Kihara, "Endothelial function and oxidative stress in cardiovascular diseases," Circulation Journal, vol. 73, no. 3, pp. 411-418, 2009.

[26] J.-I. Pagel and E. Deindl, "Disease progression mediated by Egr-1 associated signaling in response to oxidative stress," International Journal of Molecular Sciences, vol. 13, no. 10, pp. 13104-13117, 2012.

[27] F. L. Khong, Y. Zhang, A. J. Edgley et al., " 3 ', 4'-Dihydroxyflavonol antioxidant attenuates diastolic dysfunction and cardiac remodeling in streptozotocin-induced diabetic m(Ren2)27 rats," PLoS ONE, vol. 6, no. 7, Article ID e22777, 2011.

[28] V. W. T. Liu and P. L. Huang, "Cardiovascular roles of nitric oxide: a review of insights from nitric oxide synthase gene disrupted mice," Cardiovascular Research, vol. 77, no. 1, pp. 1929, 2008.

[29] F. Lacy, M. T. Kailasam, D. T. O’Connor, G. W. SchmidSchönbein, and R. J. Parmer, "Plasma hydrogen peroxide production in human essential hypertension: role of heredity, gender, and ethnicity," Hypertension, vol. 36, no. 5, pp. 878-884, 2000.

[30] W. Kosmala, R. Plaksej, J. M. Strotmann et al., "Progression of left ventricular functional abnormalities in hypertensive patients with heart failure: an ultrasonic two-dimensional speckle tracking study," Journal of the American Society of Echocardiography, vol. 21, no. 12, pp. 1309-1317, 2008. 
[31] S. Langeland, J. D’hooge, P. F. Wouters et al., "Experimental validation of a new ultrasound method for the simultaneous assessment of radial and longitudinal myocardial deformation independent of insonation angle," Circulation, vol. 112, no. 14, pp. 2157-2162, 2005.

[32] J. Wang, D. S. Khoury, Y. Yue, G. Torre-Amione, and S. F. Nagueh, "Preserved left ventricular twist and circumferential deformation, but depressed longitudinal and radial deformation in patients with diastolic heart failure," European Heart Journal, vol. 29, no. 10, pp. 1283-1289, 2008.

[33] M. R. Zile and D. L. Brutsaert, "New concepts in diastolic dysfunction and diastolic heart failure: Part I: diagnosis, prognosis, and measurements of diastolic function," Circulation, vol. 105, no. 11, pp. 1387-1393, 2002.

[34] S. F. Nagueh, C. P. Appleton, T. C. Gillebert et al., "Recommendations for the evaluation of left ventricular diastolic function by echocardiography," Journal of the American Society of Echocardiography, vol. 22, no. 2, pp. 107-133, 2009.

[35] M. Kasner, D. Westermann, P. Steendijk et al., "Utility of Doppler echocardiography and tissue Doppler imaging in the estimation of diastolic function in heart failure with normal ejection fraction," Circulation, vol. 116, no. 6, pp. 637-647, 2007.

[36] S. F. Nagueh, K. J. Middleton, H. A. Kopelen, W. A. Zoghbi, and M. A. Quiñones, "Doppler tissue imaging: a noninvasive technique for evaluation of left ventricular relaxation and estimation of filling pressures," Journal of the American College of Cardiology, vol. 30, no. 6, pp. 1527-1533, 1997.

[37] A. Z. Reznick and L. Packer, "Oxidative damage to proteins: spectrophotometric method for carbonyl assay," Methods in Enzymology, vol. 233, pp. 357-363, 1994.

[38] L. W. Oberley and D. R. Spitz, "Assay of superoxide dismutase activity in tumor tissue," Methods in Enzymology, vol. 105, pp. 457-464, 1984.

[39] P. Qu, Y. Ding, D. Xia, H. Wang, and X. Tian, "Variations in cardiac diastolic function in hypertensive patients with different left ventricular geometric patterns," Hypertension Research, vol. 24, no. 5, pp. 601-604, 2001.

[40] D.-W. Sohn, J.-M. Song, J.-H. Zo, I.-H. Chai, H.-G. Chung, and H.-S. Kim, "Mitral annulus velocity in the evaluation of left ventricular diastolic function in atrial fibrillation," Journal of the American Society of Echocardiography, vol. 12, no. 11, pp. 927931, 1999.

[41] Y. Shizukuda, C. D. Bolan, D. J. Tripodi et al., "Does oxidative stress modulate left ventricular diastolic function in asymptomatic subjects with hereditary hemochromatosis?" Echocardiography, vol. 26, no. 10, pp. 1153-1158, 2009.

[42] S. Sagar, I. J. Kallo, N. Kaul, N. K. Ganguly, and B. K. Sharma, "Oxygen free radicals in essential hypertension," Molecular and Cellular Biochemistry, vol. 111, no. 1-2, pp. 103-108, 1992. 


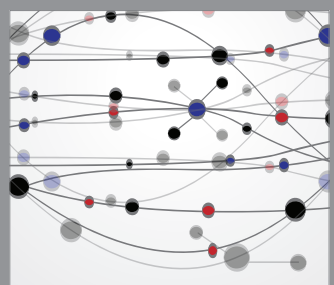

The Scientific World Journal
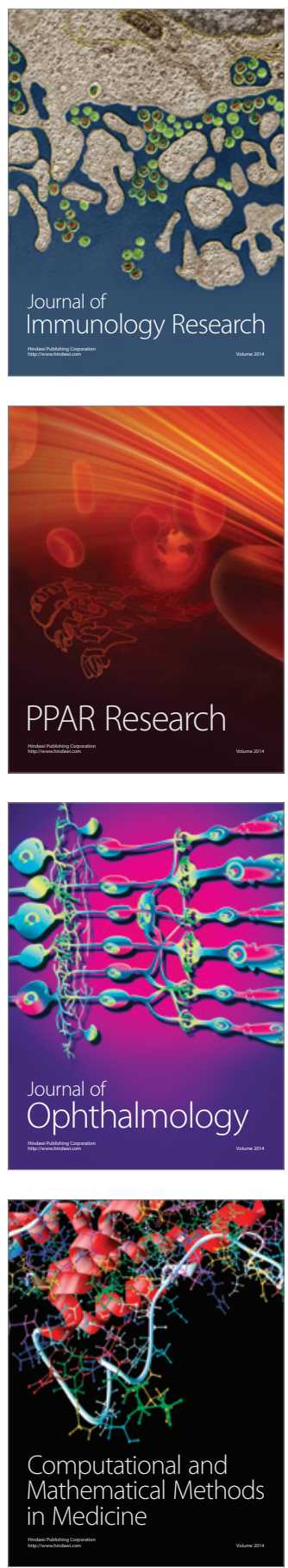

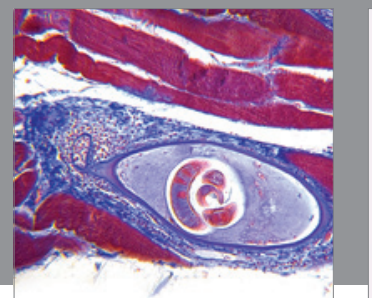

Gastroenterology

Research and Practice
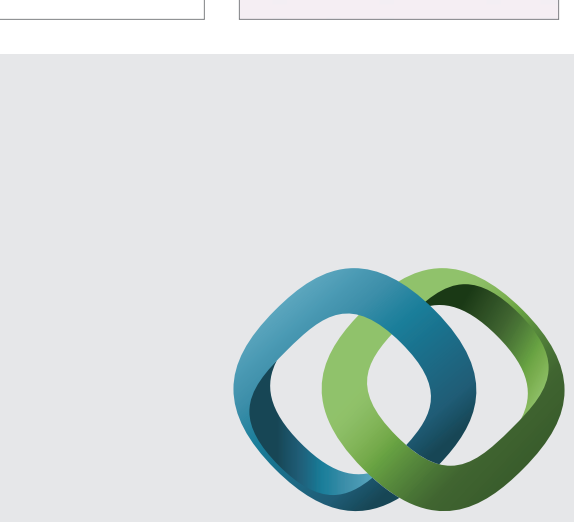

\section{Hindawi}

Submit your manuscripts at

http://www.hindawi.com
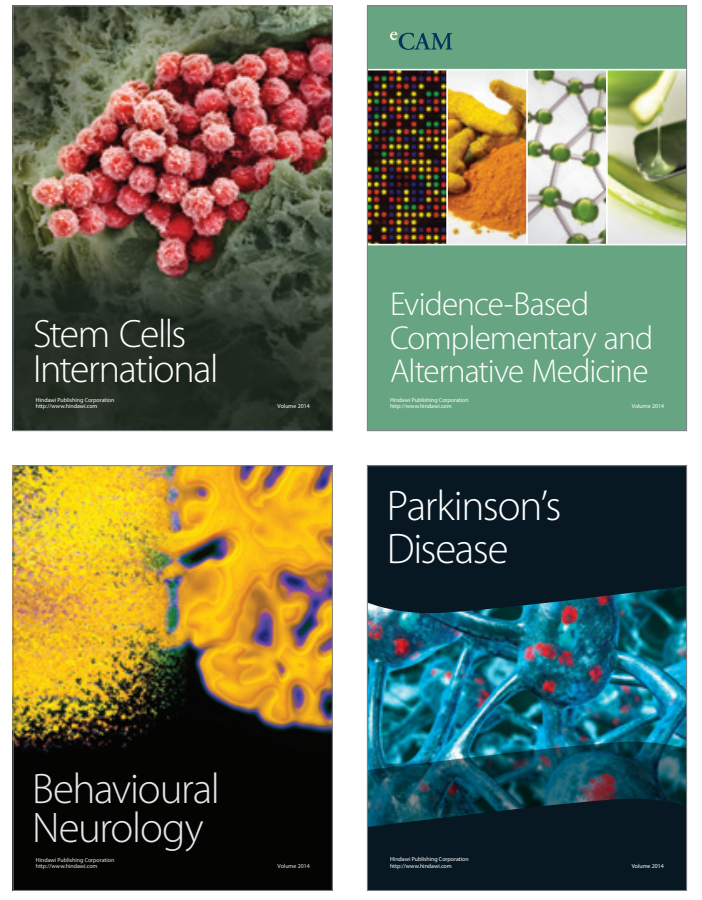
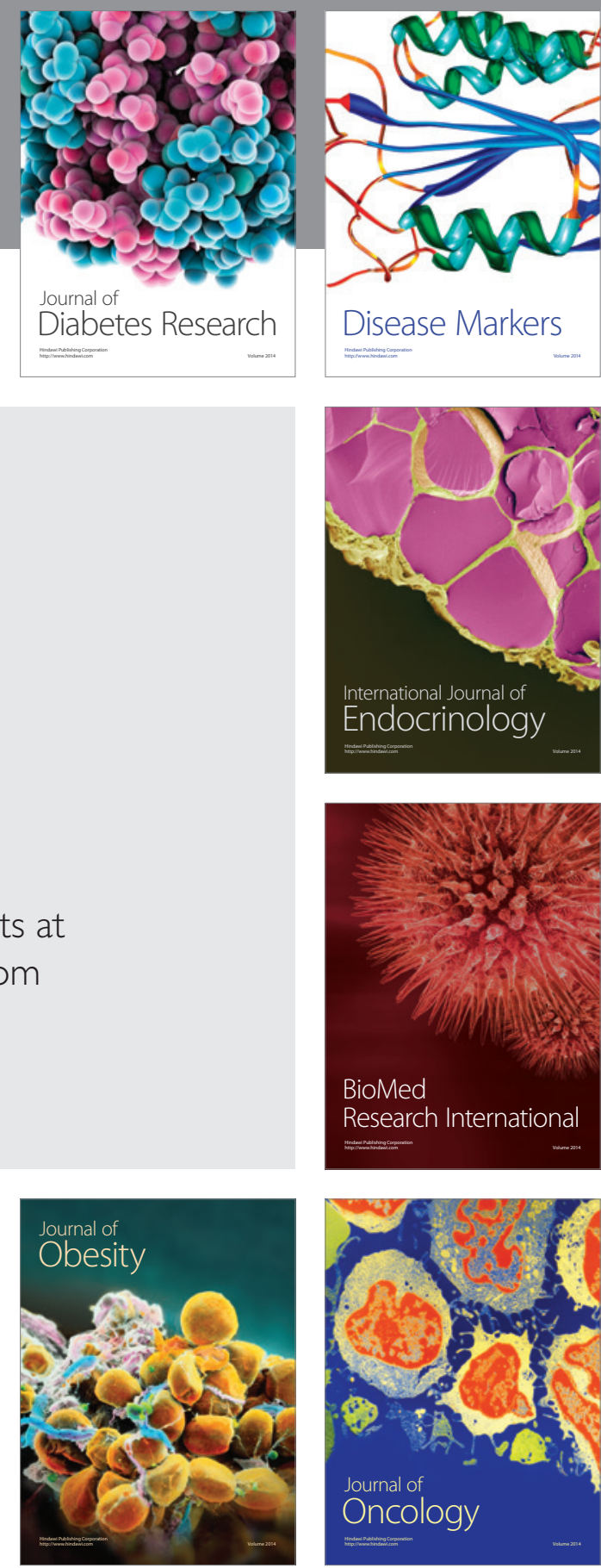

Disease Markers
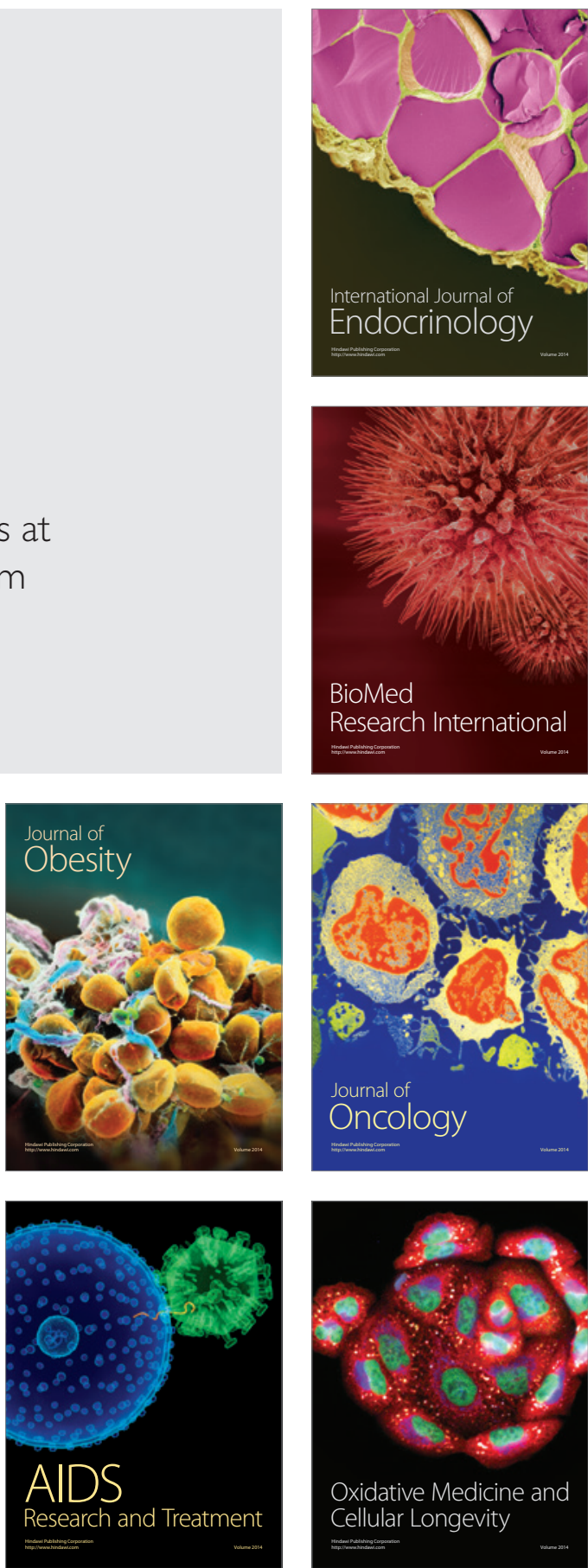